DE92 001615

\title{
STEAM PRETREATMENT FOR COAL LIQUEFACTION
}

\author{
Second Quarterly Report
}

For the Period

\section{January 1991 to 31 March 1991}

\author{
Robert A. Graff \\ Valcria Balogh-Nair \\ The City college of CUNY \\ office of Researsh Administration \\ New York, NY 10031
}

\section{Work Performed Under USDOE Contract No. DE-AC22-90PC90052 \\ Wiliiam E. Mckinstry, Program Manager}

\section{DISCLAIMER}

This report was prepared as an account of work sponsored by an agency of the United States Government. Neither the United States Government nor any agency thereof, nor any of their employees, makes any warranty, express or implied, or assumes any legal liability or responsibility for the accuracy, completeness, or usefulness of any information, apparatus, product, or process disclosed, or represents that its use would not infringe privately owned rights. Reference herein to any specific commercial product, process, or service by trade name, trademark, manufacturer, or otherwise does not necessarily constitute or imply its endorsement, recom. mendation, or fa roring by the United States Government or any agency thereof. The views and opinions of authors expressed herein do not necessarily state or reflect those of the United States Government or any agency thereof. 


\section{ACKNOWLEDGEMENTS}

Substantial contributions to the work described here were made by Graduate Research Assistants Olga E. Ivanenko and Claude Brathwaite and Technicians William Hall, Ivan Oritz, Zhen Rong Xu, and Russell Smith. 


\begin{abstract}
Steam pretreatment is the reaction of coal with steam at temperatures well below those usually used for solubilization. The objective of the proposed work is to test the application of steam pretreatment to coal liquefaction. This quarter, a $300 \mathrm{ml}$ stirred autoclave for liquefaction tests was received and installation initiated. Four coal samples were obtained from the Penn state Sample Bank. Continuous flow pretreatment procedures were reestablished. Extraction yields after pretreatment of the new sample of Illinois No. 6 coal are in agreement with previous results even though the particle size is considerably larger. Purification of the model compound B-naphthylmethyl phenyl ether has been completed. However, $\alpha$-naphthylmethyl phenyl ether has been found to undergo acid catalyzed rearrangement during purification $c_{n}$ silica. An alternative method for purification is being examined.
\end{abstract}




\section{TABLE OF CONTENTS}

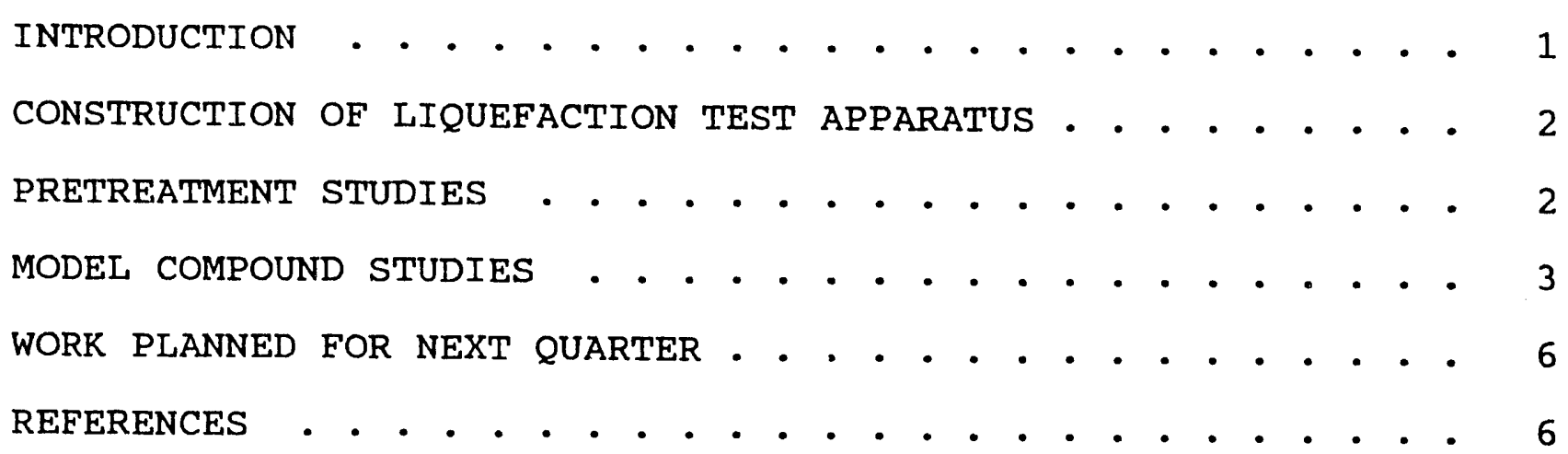




\section{INTRODUCTION}

This is the second quarterly report of a two year program on the application of steam pretreatment to the direct liquefaction of coal. Steam pretreatment is the reaction of coal with steam at temperatures well below those usually used for solubilization.

Steam pretreatment has been shown to be effective in coal pyrolysis. For steam pyrolysis, it has more than doubled the liquid yield, reduced the molecular weight of pyrolysis liquid by .1\%, and increased yields in mild extraction. Studies of pretreated Illinois No. 6 coal indicate that steam reacts with the ether linkages in coal, replacing them with hydroxyl groups. The result is a partially depolymerized coal. The oxygen content of this pretreated coal is $27 \%$ that of the feed.

These results suggest that steam pretreatment prior to solubilization will be beneficial to the coal liquefaction process. It is the objective of this work to test this application. Direct liquefaction of steam pretreated coals will be carried out in a stirred autoclave and the results compared with those from the liquefaction of raw coal.

It is also an objective of this work to develop an improved understanding of the chemistry of steam pretreatment. For this purpose, model compounds will be reacted with steam under the same conditions as used for coal pretreatment and their products analyzed to determine reaction pathways. 


\section{CONSTRUCTION OF LIQUEFACTION TEST APPARATUS}

A $300 \mathrm{ml}$ stirred autoclave was constructed by Autoclave Engineers, as ordered, and delivered on 16 January 1991. An auxiliary heater was missing from the shipment and the pickup for the magne ic drive was broken. These deficiencies have been rectified. Installation has been initiated and will be continued during the next quarter.

\section{PRETREATMENT STUDIES}

The mass spectrometer, which is needed to monitor the oxygen level in the anaerobic chamber, was restored to operation by the manufacturer.

The following coals were ordered from the Penn State Sample Bank:

$$
\begin{array}{lll}
\text { DECS } & 1 & \text { Texas lignite } \\
\text { DECS } 2 & \text { Illinois No. } 6 \\
\text { DECS } 7 & \text { Wyoming subbituminous A } \\
\text { DECS } 12 & \text { Pittsburgh hvAb }
\end{array}
$$

These samples have been received and are being stored under refrigeration in their unopened containers.

The pretreatment procedure has been reestablished using a continuous flow of steam. The apparatus and procedure are as described in Graff, Zhou and Brandes, 1988. Several tests were carried out with the new sample of Illinois No.6 coal obtained from the Penn state Sample Bank, DECS-2 (our designation CFI 27). The sample was used as received with a particle size of -20 mesh. Its moisture content was determined to be $8.0 \%$ prior to use.

Extraction yields for raw and pretreated coal are given in Table 1 based on daf raw coal; volatiles losses are not included. Extract yields for pretreated coal are double those for raw coal. This is in agreement with previous results, thereby validating presently used procedures and the condition of the new sample of Illinois No. 6 coal. These results also demonstrate that the improvement in extraction yield resulting from pretreatment is not diminished when the particle size is increased from -200 mesh to -20 mesh. The non-flow procedure, which is to be used for steam pretreatmont of model compounds, will be tested next quarter. 
Table 1

Continuous Flow pretreatment of IIlinois No. 6 Coal (CFI 27A)

$\begin{array}{cccc}\text { Run No. } & \text { Temperature } & \begin{array}{c}\text { Pressure } \\ \text { ( } 1 \text { S } i)\end{array} & \begin{array}{c}\text { Extraction Yield } \\ \text { (\%) }\end{array} \\ \text { CF 1 } & 320 & 750 & 23.1 \\ \text { CF 3 } & 350 & 750 & 28.0 \\ \text { CF 2 } & 340 & 600 & 25.0 \\ \text { R1 } & \text { raw } & & 13.1 \\ \text { R2 } & \text { raw } & & 15.8 \\ \text { R3 } & \text { raw } & & 12.7\end{array}$

\section{MODEL COMPOUND STUDIES}

Purification and testing for impurities in the second pair of model compounds, $\alpha-$ and $B-r_{a} a p h t h y l m e t h y l$ phenyl ethers ( $\alpha$ - and $\left.B-N M P E\right)$, continued during this quarter.

Preparation of these compounds was accomplished using established procedures (Maslak and Guthrie, 1986; Zarif, et al.. 1974). ${ }^{1} \mathrm{H}$ NMR spectral characterizations were consistent with reported spectra. HPLC analyses revealed purities of less than 99\%. Repeated recrystallizations/triturations in a pentane/ether mixture (100/5) gave B-NMPE in $99.96 \%$ purity. About one gram of this isomer is now on hand for pretreatment tests. This procedure, however, failed to produce purities greater than $98.5 \%$ when applied to $a$-NMPE.<smiles>c1ccc(OCc2cccc3ccccc23)cc1</smiles><smiles>c1ccc(OCc2ccc3ccccc3c2)cc1</smiles>

a-naphthylmethyl phenyl ether $B$-naphthylmethyl phenyl ether Flash column chromatography performed on a-NMPE (silicahexane/ether) produced unexpected results. HPIC analysis revealed the presence of a second compound (labelled A) in substantial amounts (Figure 1). The quantity of A shown in the HPLC trace is not comparable to that seen in the ${ }^{1} \mathrm{H}$ NMR spectrum (Figure 2). 


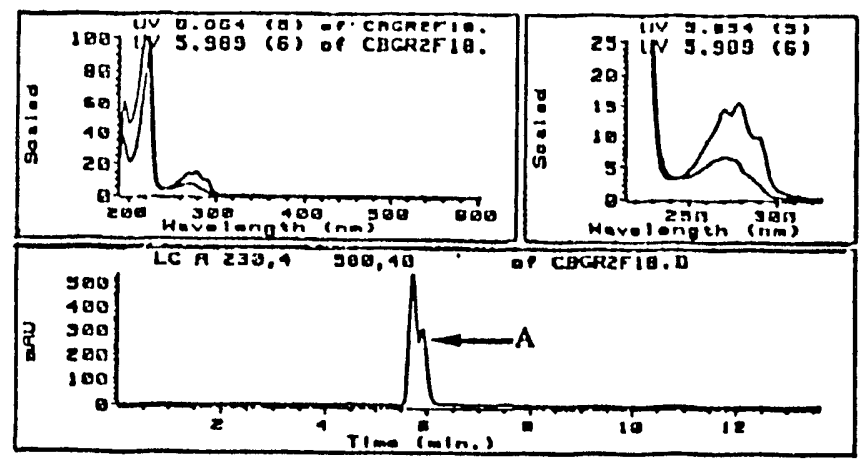

Figure 1. HPLC profile of $98.5 \%$ pure $\alpha$-NMPE after flash column chromatography.

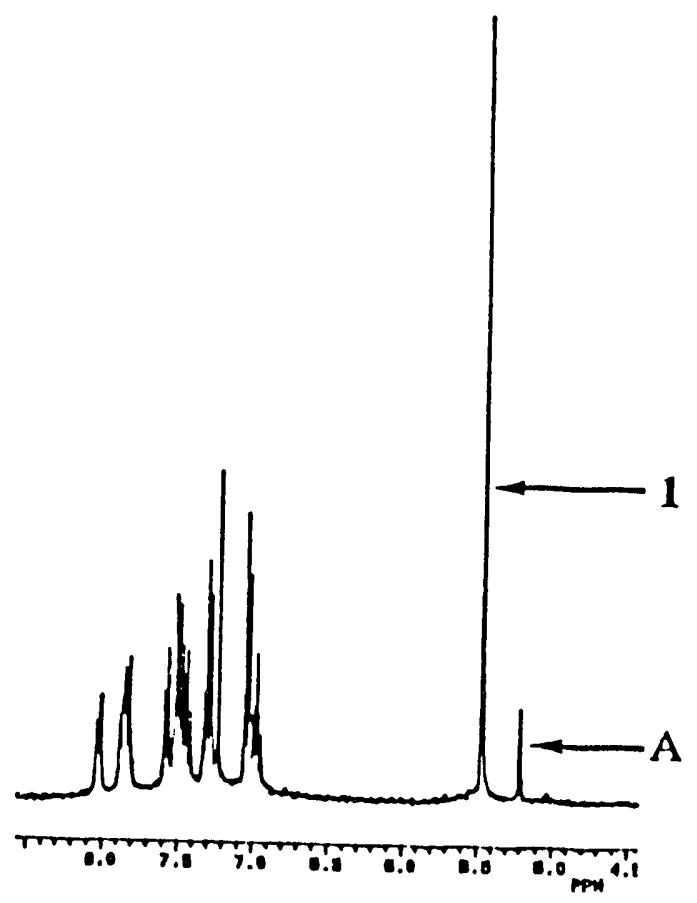

Figure 2. ${ }^{1} \mathrm{H}$ NMR of pure $\alpha$-NMPE (1) after flash column chromatography. 
The HPLC data were tested and found to be reproducible at different sample concentrations and solvent compositions, ruling out system artifacts. The aberrant electronic behavior of naphthalenes (related to fine structure and $\varepsilon$ values at different concentrations) Inay explain the discrepancy between the NMR and HPLC data. Because of these properties, HPLC profiles were taken at three different wavelengths and compared to avoid erroneous conclusions.

It was determined that the chemical transformation which occurred during the isolation of $\alpha-\mathrm{NMPE}$ is not photochemical in nature, a thermal equilibrium of conformational isomers, or a result of solvent contamination. Compound $A$ emerged only after attemnted purification using silica (hexane/ether). Its formation may be the result of an acid catalyzed rearrangement of a-NMPE (Moshchinskaya, et al., 1959). Alternative chromatographic methods will be developed next month to circumvent this problem. It is evident that, even after repeated crystallization, one can not rely solely on spectral characterization to determine the integrity of a sample.

Working on a small scale with basic alumina, $\alpha$-NMPE was obtained in close to $100 \%$ purity. Previous isolation procedures relied entirely on recrystallization from ethanol (Maslak and Guthrie, 1986). This method is incapable of producing the $99.9+\%$ purity that is needed for this study. Repeated crystallizations followed by trituration and flash column chromatography (silica-hexane) led to disastrous results caused by the acid catalyzed rearrangement of 1 (Moshchinskaya, et al., 1959). Exploratory work using basic alumina (ether-hexane) combined with repeated recrystallization gave very good results. The possible acid catalyzed rearrangement was circumvented (Figure 3 ).

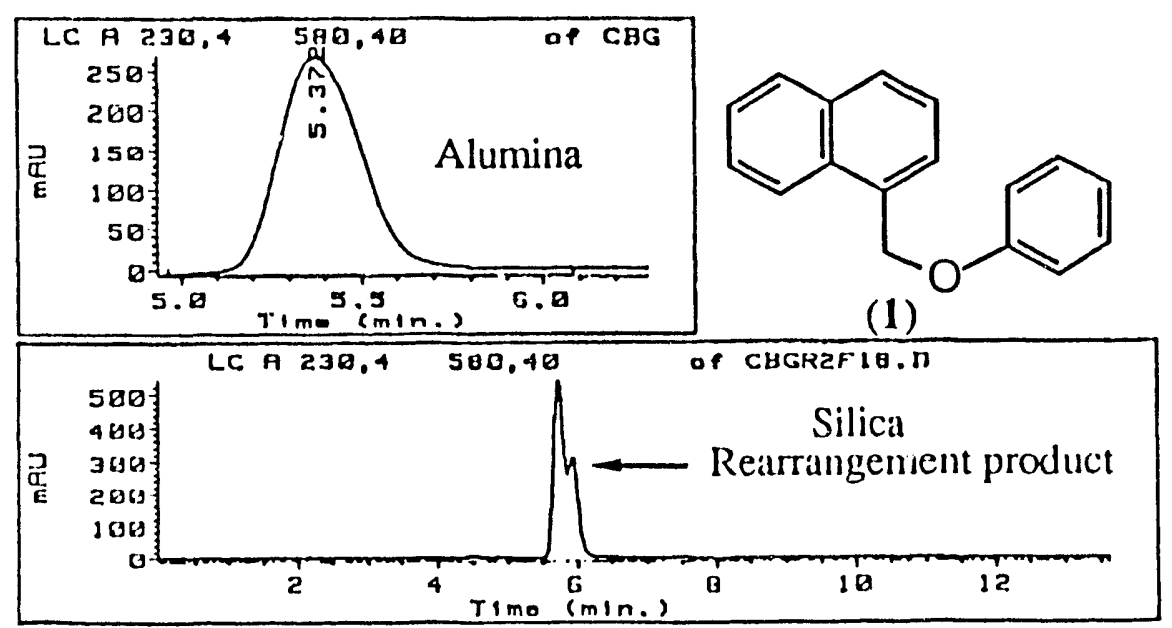

Figure 3. HPLC profile of alpha-naphthyl methyl phenyl ether isolation. 
The stability of, a-NMPE at room temperature in the presence of light is questionable. At present a rapid preparative separation procedure using Flash Alumina is being worked out to isolate large amounts of this compound.

\section{WORK PLANNED FOR NEXT QUARTER}

Installation of the autoclave will continue next quarter. A nonflow procedure for pretreatment of model compounds will be tested. Purification of the fourth model compound, $\alpha$-naphthylmethyl phenyl ether, will be completed.

\section{REFERENCES}

1. Graff, R.A., P. Zhou, and S.D. Brandes, 1988, "Steam Conditioning of Coal for Synfuels Production," Final Report for 1987 to 1988 , U.S. Department of Energy, Contract No. DE-AC21-87MC23288.

2. Maslak, P. and Guthrie, R.D., 1986, J.Am.Chem.Soc., 108, 2637 .

3. Moshchinskaya,N.K.; Bouden,B.S.; Krukovskii,S.P., Lakhmachuk,L.S.; Molosnova,V.P.; Chertok,E.P., 1959, Izv. vyssh. ucheb. Zaved. Khim, i Khim. Tekhnol., 2, 790; Chem. Abstr., 1960, 54, 8716 .

4. Zarif, M., A. Badr and H.A.H. El-Sherief, 1974, Indian J. Chem., 12, 1067 . 

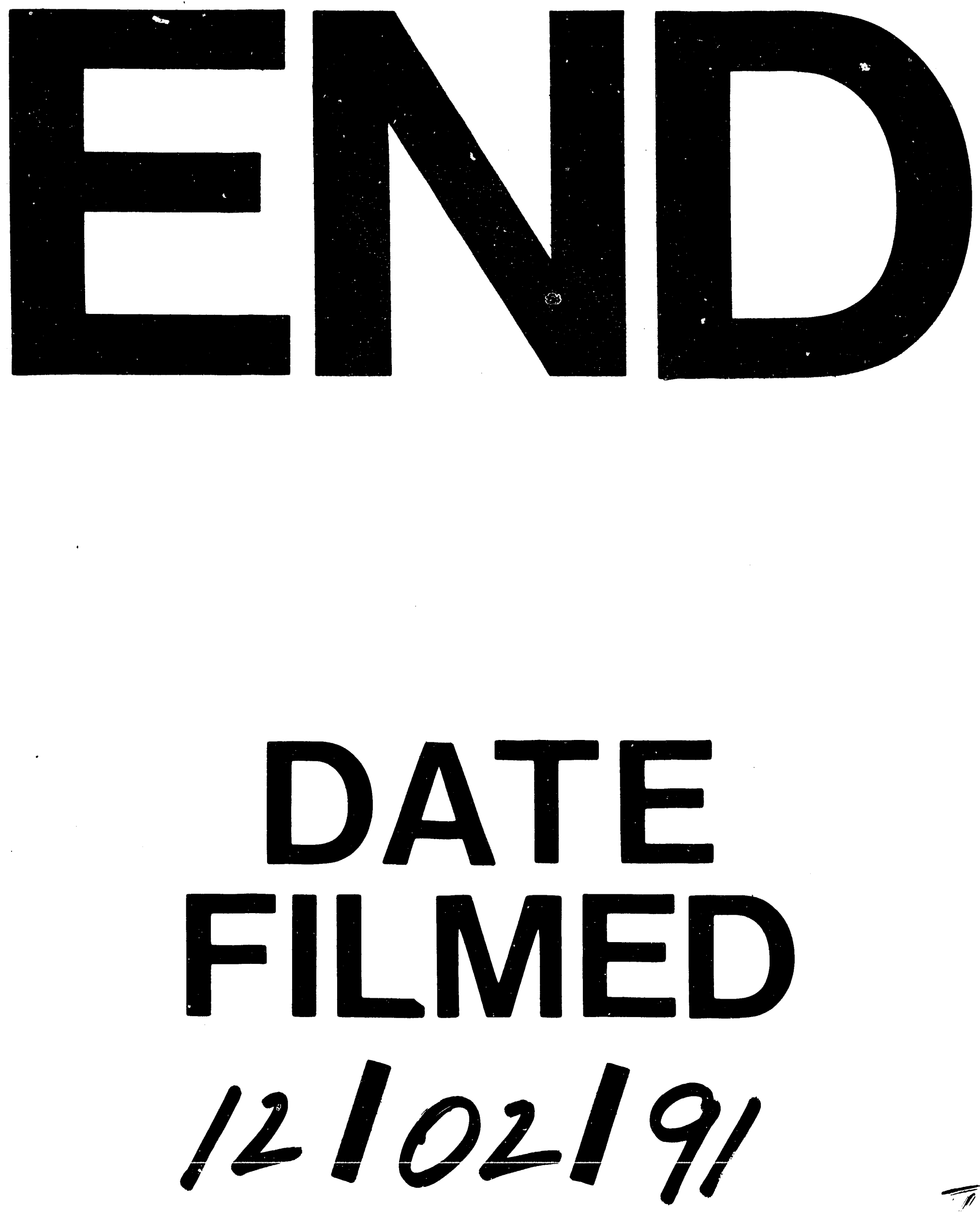

I 
